\title{
Comparative Effects of Stevia rebaudiana and Aspartame on hepato-renal function of diabetic rats: Biochemical and Histological Approaches
}

\author{
Azza H. AbdElwahab ${ }^{1}$, Asmaa F. Yousuf ${ }^{1}$, Basma K. Ramadan ${ }^{1}$, Hanan Elimam ${ }^{2 *}$ \\ ${ }^{1}$ Physiology Department, Faculty of Medicine (Girls), Al-Azhar University, Cairo, Egypt. \\ ${ }^{2}$ Biochemistry Department, Faculty of Pharmacy, University of Sadat City, Sadat City, Egypt.
}

\begin{tabular}{|c|c|}
\hline ARTICLE INFO & ABSTRACT \\
\hline $\begin{array}{l}\text { Article history: } \\
\text { Received on: } 24 / 05 / 2017 \\
\text { Accepted on: } 14 / 07 / 2017 \\
\text { Available online: } 30 / 08 / 2017\end{array}$ & $\begin{array}{l}\text { Diabetes mellitus is a chronic syndrome affecting many systems of the body and may be considered as a leading } \\
\text { cause of death globally. To compare the efficacy of Stevia rebaudiana and Aspartame on hepato-renal functions, } \\
\text { sixty adult male albino rats were divided into } 6 \text { groups; control, Stevia, Aspartame, diabetic, diabetic-treated } \\
\text { with Stevia and diabetic-treated with Aspartame. Food consumption, body weight, blood glucose, serum }\end{array}$ \\
\hline $\begin{array}{l}\text { Key words: } \\
\text { Stevia rebaudiana, } \\
\text { Aspartame, Alloxan, } \\
\text { Hepato-renal functions, } \\
\text { Diabetes mellitus. }\end{array}$ & $\begin{array}{l}\text { levels were determined. Hepatic malondialdehyde (MDA), glutathione (GSH) and bcl-2 levels were assessed as } \\
\text { well as histological examination for liver and kidney sections were performed. Treatment of diabetic rats with } \\
\text { Stevia leaf extract or Aspartame significantly lowered food consumption and serum blood glucose. Serum blood } \\
\text { glucose was significantly decreased by } 38 \% \text { with Stevia treatment and } 50 \% \text { with Aspartame. Stevia treatment of } \\
\text { diabetic rats significantly lowered the serum level of ALT by } 62 \% \text {, AST by } 57 \% \text {, ALP by } 41 \% \text {, urea by } 16 \% \\
\text { and creatinine by } 65 \% \text {. Hepatic MDA was reduced by } 50 \% \text { in diabetic group treated with Stevia and hepatic } \\
\text { GSH and Bcl-2 levels were significantly elevated. In contrast, Aspartame did not change these parameters. } \\
\text { Histopatholgically, diabetic rats treated with Stevia showed improvement of liver and renal tissues, while } \\
\text { Aspartame treatment augmented alloxan induced tissue destruction. Aspartame was more effective } \\
\text { hypoglycemic agent than Stevia in diabetic rats but Stevia showed protective effects on the liver and kidney } \\
\text { functions. Stevia rebaudiana may be therapeutically beneficial as hepato-renal protective agent for those } \\
\text { suffering from diabetes mellitus. }\end{array}$ \\
\hline
\end{tabular}

\section{INTRODUCTION}

Diabetes, a chronic metabolic disorder of carbohydrates, is the seventh leading cause of death worldwide which needs care and attention. By the year 2025, the diabetic population is expected to increase to 300 million or more, according to World Health Organization (Wild et al., 2004). Dietary behaviors such as a dietary intake pattern, including

\footnotetext{
* Corresponding Author

Hanan Elimam, Department of Biochemistry, Faculty of Pharmacy, University of Sadat City, Sadat City, Menofia, Egypt.

Email: Hanan.Elimam @ fop.usc.edu.eg
}

sugar consumption, have been proved to have an essential role on weight gain of healthy individuals (Bray et al., 2004). Avoiding intake of concentrated sugar is important for healthy and diabetic persons in improving health and maintaining normal blood glucose level. Replacing sugar with nonnutritive sweeteners can help in weight managing and blood glucose level control by providing sweet taste without calories (Abo Elnaga et al., 2016). In the past few decades, the intake of foods and beverages containing nonnutritive sweeteners has intensely increased (Mattes and Popkin, 2009). Aspartame (L-aspartyl-L-phenylalanine methyl ester), is one of the most commonly used nonnutritive sweeteners, popular in more than 90 countries in about 6000 products (Magnuson et al., 2007). 
After oral administration, Aspartame is metabolized into three constituents, two amino acids (50\% phenylalanine and $40 \%$ aspartic) and $10 \%$ methanol. Aspartame produces effects through its metabolites, small amounts of Aspartame can greatly increase the concentration of methanol in the blood. Methanol has a relatively low toxicity, but its metabolites are very toxic. Some studies demonstrate that Aspartame decreases food intake and helps with weight control (De la Hunty et al., 2006). Others, however, suggest that Aspartame may stimulate appetite leading to weight gain (Swithers and Davidson, 2008). There is presently no official recommendation regarding the use of nonnutritive sweeteners for weight management, due to mixed findings. The association between Aspartame intake and some side effects such as headache, nausea, irritability, and tachycardia has been hypothesized (Van den Eeden et al., 1994). Therefore, the safety of Aspartame has been questioned.

Stevia is nature's sweetest gift from the Amazon rainforest. It belongs to the family Asteraceae (Compositae) (Zaman et al., 2015). Stevia sweeteners, as crude extract from leaves, have been used from decades to sweeten soy sauce, soft drinks, yogurt, and other foods in Brazil, Japan, and Korea. Stevia leaves contain glycosides, which produce a sweet taste but have no caloric value. The dry extract from the leaves of Stevia also contains alkaloids, flavonoids, hydroxycynnamic acids, watersoluble xanthophylls and chlorophylls, neutral water-soluble oligosaccharides, amino acids, lipids and essential oils (Shukla $e t$ al., 2011).

The Stevia leaves have sensory and functional properties higher than those of many other high-potency sweeteners and have the potential in becoming a major source of natural sweetener for the growing food industry (Goyal et al., 2010). Stevia has been found to improve insulin sensitivity in rodent models and has beneficial effects on levels of blood glucose and insulin in human studies, which suggests it may have a role in regulating food consumption (Gregersen et al., 2004).

Stevia leaves have many other medical applications like antimicrobial, antiviral, antifungal, anti-diarrheal, hypoglycemic, antihypertensive, anti-inflammatory, anti-tumor and immunomodulatory effects (Chatsudthipong and Muanprasat, 2009; Gupta et al., 2013). Based on toxicological studies, secondary metabolites present in Stevia do not have teratogenic, mutagenic or carcinogenic effects and no allergic effects have been found after digesting it as a sweetener (Pol et al., 2007). In 2010, a clinical study reported that, Stevia preloads significantly decreased postprandial glucose levels in comparison to sucrose preloads (Anton et al., 2010).

Previously, it has been claimed that consumption of Aspartame could cause behavioural and neurological disturbances in sensitive individuals (Humphries et al., 2008). Some studies have associated artificial sweeteners, Aspartame, with health disorders such as hepatotoxicity (Abhilash et al., 2011) and cancer (Whitehouse et al., 2008).

These data about toxicity and safety of Aspartame has motivated us to design this research proposal attempting to compare the efficacy of Stevia and Aspartame on hepato-renal functions of diabetic rats induced by alloxan.

\section{MATERIALS AND METHODS}

\section{Animals}

Sixty adult male albino rats of local strain aged 2-3 months and weighting 160-200 gm were used. Rats were purchased from Abo-Rawash, Cairo, Egypt. All rats were left to adapt to new environmental conditions for one week. 2-4 rats were housed in each cage and kept in a well-ventilated room under conditions of natural light and dark cycle. The cages were $20.0 \times$ $59.5 \times 38.0 \mathrm{~cm}$. All experimental rats had free access to water provided ad libitum and were fed a standard pellet diet. Rats were fasted for eighteen hours prior to alloxan administration allowing access to water. All procedures were approved by the ethical committee of Alazhar University. The "Principles of laboratory animal care" and the specific national laws were followed, where applicable.

\section{Drugs}

- Alloxan monohydrate (Algomhoria Chemical, Cairo, Egypt), a well-known diabetogenic agent widely employed for inducing type-II diabetes in rats (Viana et al., 2004). A $2 \%$ alloxan solution diluted in $0.9 \%$ normal saline (Carvalho et al., 2003) was injected intra-peritoneal, to overnight fasted rats $(75 \mathrm{mg} / \mathrm{kg} \mathrm{b}$. wt.) for 5 consecutive days (Suresh and Das, 2001). Rats resumed feeding and drinking 30 minutes after the drug administration.

- Stevia leaves were collected and extract was prepared in the National Research Center (Dokki, Cairo, Egypt). Briefly, $50 \mathrm{~g}$ of air-dried Stevia rebaudiana leaves were finely grinded and extracted with $500 \mathrm{ml}$ of ethanol by using soxhlet apparatus. Crude extract was filtered, and evaporated under low pressure. The residual extract (200 $\mathrm{mg} / \mathrm{kg} \mathrm{b}$. wt.) was suspended in $0.9 \% \mathrm{w} / \mathrm{v}$ saline and administered orally (Shukla et al., 2011).

- Aspartame tablets (Amriya pharmaceutical, Alexandria, Egypt) were dissolved in distilled water and given orally (250 mg/kg b. wt.) (Niedowicz and Daleke, 2005).

\section{Experimental design:}

Rats were randomly divided into 6 groups (10 rats each).

- Group I: Rats were fed balanced diet, and used as control.

- Group II: Rats were treated with Stevia $200 \mathrm{mg} / \mathrm{kg}$ b. wt., daily for 6 weeks (Shukla et al., 2011).

- Group III: Rats were treated with Aspartame $250 \mathrm{mg} / \mathrm{kg}$ b. wt. daily for 6 weeks (Alkafafy Mel et al., 2015).

- Group IV: After 18 hours of fasting, body weight and blood glucose level of each rat in this group were measured. Rats were subjected to induction of diabetes by intra-peritoneal injection of alloxan monohydrate at a dose of $75 \mathrm{mg} / \mathrm{kg} \mathrm{b}$. wt. for 5 consecutive days (Suresh and Das, 2001). To minimize/prevent mortality of the rats, $50 \%$ dextrose-saline 
solution was injected subcutaneously within $2 \mathrm{~h}$ of alloxan administration (Federiuk et al., 2004). Following the diabetes induction, blood was drawn from the tail vein of rats to determine their fasting blood glucose levels. Rats with blood glucose level exceeding $320 \mathrm{mg} / \mathrm{dl}$ were selected for the treatments, (saline, group IV).

- Group V: Diabetic rats treated with Stevia, $200 \mathrm{mg} / \mathrm{kg} \mathrm{b}$. wt., daily for 6 weeks.

- Group VI: Diabetic rats treated with Aspartame, $250 \mathrm{mg} / \mathrm{kg} / \mathrm{b}$. wt., daily for 6 weeks.

\section{Determination of food consumption and body weight}

Food intake and weight gain monitored weekly for each rat of each group with electric balance at approximately the same time for 6 weeks.

\section{Blood Samples Collection}

Under light ether anesthesia, on the day of the experiment, blood samples were collected, from retro-orbital sinus by capillary tubes, in a centrifuge tube and left to clot for $1 \mathrm{~h}$ at room temperature, and then centrifuged at $3000 \mathrm{rpm}$ for fifteen minutes. The separated sera were analyzed for estimation of serum ALT, AST, ALP, Urea, and Creatinine.

\section{Biochemical assay}

1. Serum aminotransferases (ALT \& AST) were determined by using the colorimetric method of Reitman-Frankel (Reitman and Frankel, 1957).

2. Serum alkaline phosphatase (ALP) was determined by using the phenolphthalein monophosphate method (Babson et al., 1966).

3. Serum glucose levels according to Trinder, (1969) using glucose enzymatic (GOD-PAP)-liquizyme Kits (Biotechnology, Egypt).

4. Serum urea was determined by using modified Berthelotsearcy method (Henry, 1991).

5. Serum creatinine activity was assessed by using the application of Jaffe's reaction (Toora and Rajagopal, 2002).

\section{Preparation of Liver Tissue Homogenate}

The liver of the sacrificed rats was excised and cut into small pieces (1 gm). Liver samples were minced and then homogenized in $1 \mathrm{ml}$ lysis buffer [20 mM HEPES ( $\mathrm{pH} 7.5$ ), 150 $\mathrm{mM} \mathrm{NaCl}, 1 \% \mathrm{NP}-40,0.1 \%$ SDS, $1 \mathrm{mM}$ EDTA, and $1.0 \mathrm{mM}$ DTT] with protease inhibitors $(2 \mu \mathrm{g}$ each of leupeptin, aprotinin, pepstatin A, and $0.5 \mathrm{mM}$ phenylmethylsulfonyl fluoride), incubated on ice for $30 \mathrm{~min}$, and then centrifuged at $10,000 \mathrm{xg}$ at $4^{\circ} \mathrm{C}$ for $20 \mathrm{~min}$ (Ahmed et al., 2013). Cell lysates were stored at $-70^{\circ} \mathrm{C}$ until used for further analysis.

\section{Assessment of Liver Oxidative Profile}

Malondialdehyde (MDA) levels in the liver homogenate was assayed for products of lipid peroxidation by observing thiobarbituric acid reactive substance formation (Buege and Aust,
1978) using commercial kit"Biodiagnostic, Egypt". Hepatic GSH levels were assayed calorimetrically by the method developed by (Aykac et al., 1985), using commercial kit "Biodiagnostic, Egypt".

\section{Assessment of Apoptosis in the Liver}

Bcl-2 protein content was measured in liver lysates by employing the quantitative sandwich enzyme immunoassay technique using ELISA kits supplied by Uscn Life Science Inc. (Ahmed et al., 2013). The procedure was performed according to manufacturer's instructions. Levels were expressed as ng/mg protein in tissue.

\section{Histological examination}

Animals were anesthetized by ether. A dorsal midline incision was made to reach renal bed and rapidly remove the kidneys, in addition to the removal of liver tissues. The specimens were fixed in $10 \%$ neutral buffered formalin then cut to obtain 6 $\mu \mathrm{m}-$ thick paraffin sections. The sections were stained with Harris, hematoxylin and eosin stain $(\mathrm{H} \& \mathrm{E})$ for routine histological examination (Gill, 2010).

\section{Statistical analysis}

Data is expressed as Mean \pm Standard Error of Mean [SEM]. Statistical analysis was conducted using one-way analysis of variance [ANOVA] and Bonferroni post hoc multiple comparison test using SPSS [version 12]. The values of $\mathrm{P}<0.05$ were considered as statistically significant.

\section{RESULTS}

Effects of Stevia or Aspartame administration on food consumption, body weight, and blood glucose levels of control and diabetic rats

Stevia and Aspartame treated rats showed a significant reduction in food consumption by $23 \%$ and $9 \%$, respectively in comparison to control rats $(\mathrm{P}<0.05)$. Stevia and Aspartame treated rats showed a significant reduction in body weight by $27 \%$ and 18 $\%$ respectively, compared to control rats $(\mathrm{P}<0.05)$. However, serum blood glucose didn't changed $(\mathrm{P}>0.05)$ when compared control rats with both treatments. Alloxan administration to control rats resulted in significant increase in food consumption by $20 \%$ and increase in serum blood glucose levels by 333\%. These changes in diabetic group were associated with a slight decrease in body weight compared to control (Table 1).

Treatment of diabetic group with Stevia or Aspartame significantly decreased food consumption by $24 \%$ and $13 \%$ respectively. Serum blood glucose was significantly decreased by $38 \%$ with Stevia treatment and 50\% with Aspartame treatment when compared to diabetic group (Table 1).

However, this improvement did not reach basal levels of their corresponding groups $(\mathrm{P}<0.05)$. Notably, food consumption is significantly higher in diabetic rats treated with Aspartame than in diabetic rats treated with Stevia. Although, serum blood glucose in diabetic rats treated with Aspartame is lower than diabetic rats treated with Stevia (Table 1). 
Table 1: Effects of Stevia or Aspartame administration on blood glucose level, food consumption and body weight of diabetic rats.

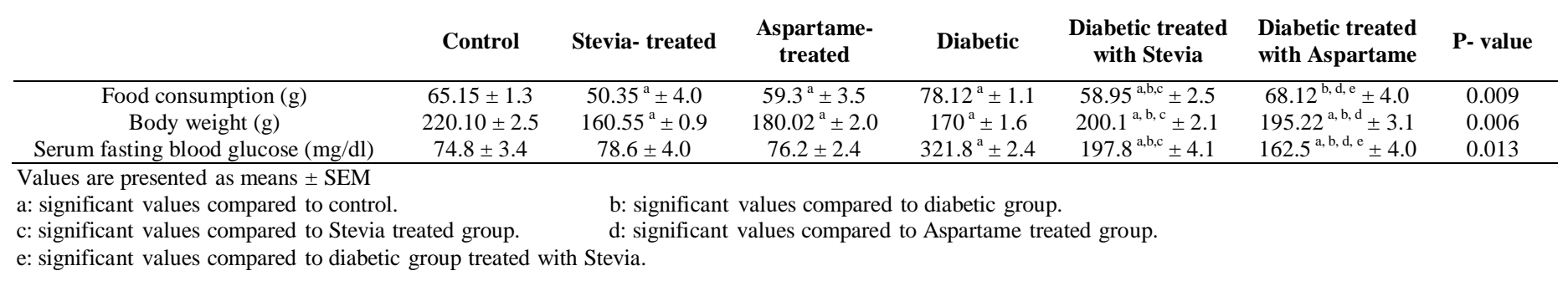

Table 2: Effects of Stevia or Aspartame administration on liver and kidney functions (serum ALT, AST, ALP, Urea and Creatinine) of diabetic rats.

\begin{tabular}{|c|c|c|c|c|c|c|c|}
\hline & Control & Stevia- treated & Aspartame-treated & Diabetic & $\begin{array}{c}\text { Diabetic-treated } \\
\text { with Stevia }\end{array}$ & $\begin{array}{l}\text { Diabetic-treated } \\
\text { with Aspartame }\end{array}$ & P-value \\
\hline ALT (U/L) & $21.6 \pm 0.7$ & $23.1 \pm 1.3$ & $70.03^{a} \pm 5.7$ & $119.1^{\mathrm{a}} \pm 11.7$ & $44.8^{\mathrm{a}, \mathrm{b}, \mathrm{c}} \pm 6.7$ & $123.1^{\mathrm{a}, \mathrm{d}, \mathrm{e}} \pm 13.1$ & 0.002 \\
\hline $\operatorname{AST}(\mathrm{U} / \mathrm{L})$ & $13.4 \pm 0.7$ & $13.9 \pm 1.8$ & $55.2^{\mathrm{a}} \pm 8.2$ & $287.4^{\mathrm{a}} \pm 16.4$ & $123.3^{\mathrm{a}, \mathrm{b}, \mathrm{c}} \pm 11.3$ & $294.4^{\mathrm{a}, \mathrm{d}, \mathrm{e}} \pm 23.46$ & 0.000 \\
\hline ALP (U/L) & $128.6 \pm 2.0$ & $131.7 \pm 6.7$ & $226.7^{\mathrm{a}} \pm 14.6$ & $249.07^{\mathrm{a}} \pm 38.7$ & $146.28^{\mathrm{a}, \mathrm{b}, \mathrm{c}} \pm 6.7$ & $254.7^{\mathrm{a}, \mathrm{d}, \mathrm{e}} \pm 14.7$ & 0.001 \\
\hline $\operatorname{Urea}(\mathrm{mg} / \mathrm{dl})$ & $31.5 \pm 5$ & $35.6 \pm 1.8$ & $61.1^{a} \pm 9.4$ & $62.4^{\mathrm{a}} \pm 4.5$ & $52.6^{\mathrm{a}, \mathrm{b}, \mathrm{c}} \pm 2.7$ & $69.9^{\mathrm{a}, \mathrm{e}} \pm 5.5$ & 0.002 \\
\hline Creatinine(mg/dl) & $0.15 \pm 0.02$ & $0.18 \pm 0.07$ & $1.7^{\mathrm{a}} \pm 0.1$ & $1.45^{\mathrm{a}} \pm 0.3$ & $0.52^{\mathrm{a}, \mathrm{b}, \mathrm{c}} \pm 0.1$ & 1. $5^{\mathrm{a}, \mathrm{e}} \pm 0.1$ & 0.001 \\
\hline
\end{tabular}

Values are presented as means \pm SEM

a: significant values compared to control. $\quad$ b: significant values compared to diabetic group.

c: significant values compared to Stevia treated group. d: significant values compared to Aspartame treated group.

e: significant values compared to diabetic group treated with Stevia.

\section{Effects of Stevia or Aspartame administration on liver functions (ALT, AST, ALP) of control and diabetic rats}

To investigate the effect of Stevia or Aspartame administration on liver function, the serum levels of ALT, AST and ALP were measured. Stevia-treated rats showed no change in ALT, AST and ALP levels when compared to control rats, while Aspartame-treated rats showed significant increase in ALT, AST and ALP levels by 3.3, 4.2 and 1.8 folds respectively (Table 2).

Liver enzymes were highly elevated in diabetic rats in comparison to control rats. Treatment of diabetic rats with Stevia significantly lowered ALT, AST and ALP levels. However, Aspartame had no effect on the levels of these enzymes. Stevia treatment of diabetic rats lowered ALT by $62 \%$, AST by $57 \%$ and ALP by $41 \%$ (Table 2).

Furthermore, by comparing the liver functions in both Stevia-treated diabetic and Aspartame-treated diabetic groups, we found that Stevia had significantly prominent reduction in serum ALT, AST, ALP levels $(\mathrm{P}<0.05)$ (Table 2$)$

\section{Effects of Stevia or Aspartame administration on kidney functions (Urea and Creatinine) of control and diabetic rats}

Both serum urea and creatinine levels were estimated to investigate the effect of Stevia or Aspartame administration on kidney function. Aspartame administration, unlike Stevia, showed a significant elevation $(\mathrm{P}<0.05)$ in urea and creatinine levels in comparison to control (Table 2).

Alloxan-induced diabetic group showed a significant deterioration in kidney function, as demonstrated by the elevation of urea levels 2 folds and creatinine levels 10 folds, compared to control rats.

Treatment of diabetic rats with Stevia significantly ameliorated renal function. The serum urea levels decreased by
$16 \%$ and creatinine decreased by $65 \%$. Aspartame treatment of diabetic rats did not improve kidney function (Table 2).

\section{Effects of Stevia or Aspartame administration on hepatic MDA, GSH and bcl-2 in control and diabetic rats: Hepatic MDA}

Aspartame administration, but not Stevia, significantly elevated the MDA levels in the liver tissues. The hepatic MDA levels of the alloxan-treated group were significantly increased 3 folds compared to control group. These changes tend to be improved towards normal levels with Stevia-treated diabetic rats when compared to diabetic group, but could not reach to the control or Stevia-treated rats. Elevation in hepatic MDA levels was noticed with Aspartame-treated diabetic rats $(60.12 \mathrm{nmol} / \mathrm{mg}$ protein) compared to diabetic group (50.25 nmol/mg protein) (Fig. $1 \mathrm{~A})$.

\section{Hepatic GSH}

Hepatic GSH in rats that received Stevia extract for six weeks showed no changes when compared to control rats, while Aspartame administration induced significant $(\mathrm{P}<0.05)$ reduction (44\%) in GSH levels. In addition, the hepatic MDA levels of the alloxan-treated group were decreased by a similar percentage as Aspartame group. Compared to diabetic rats, GSH levels showed significant $(\mathrm{P}<0.05)$ increase 1.6 folds with Stevia-treated diabetic group, unlike Aspartame-treated diabetic rats (Fig. 1 B).

\section{Hepatic bcl-2}

Stevia had no effect on hepatic level of bcl-2. Rats treated with Aspartame had significant $(\mathrm{P}<0.05)$ low levels of bcl$2,56 \%$ less than control rats. Diabetic rats showed lower levels of bcl-2 compared to control rats. Compared to diabetic rats, Stevia- 
treated diabetic group demonstrated significant $(\mathrm{P}<0.05)$ increase in bcl-2 levels 1.8 folds, although more reduction in bcl-2 was observed with Aspartame-treated diabetic rats (Fig. $1 \mathrm{C}$ ).

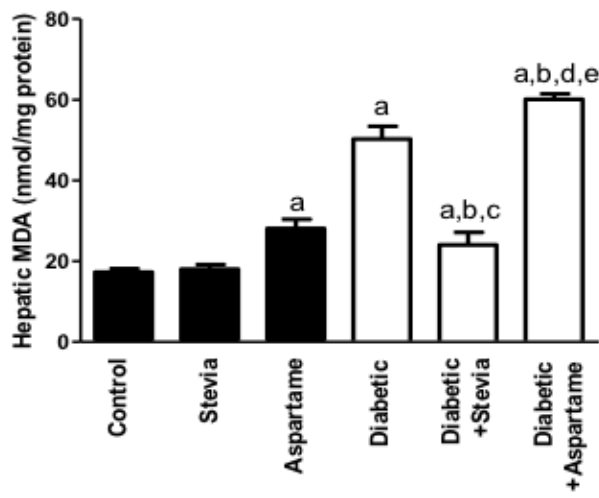

A) Hepatic MDA

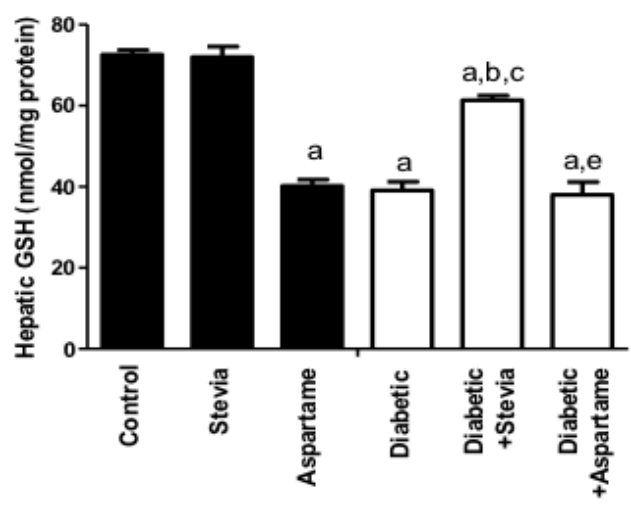

B) Hepatic GSH

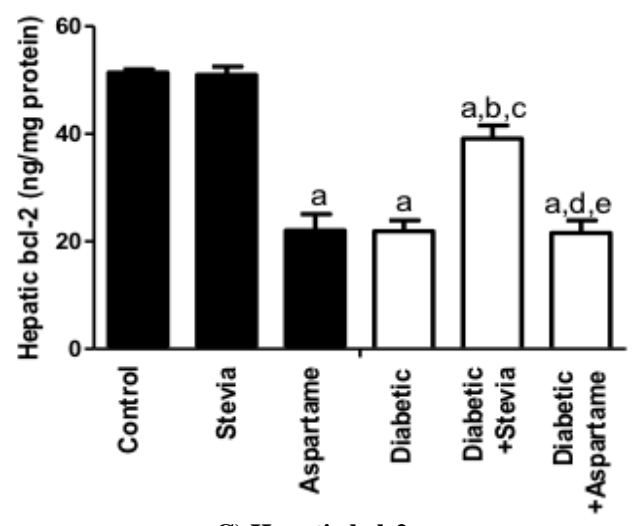

C) Hepatic bcl-2

Fig. 1: Effects of Stevia and Aspartame administration on hepatic oxidative stress (MDA; panel A and GSH; panel B) and apoptotic (bcl-2; panel C) markers in diabetic rats. (A) Stevia administration did not increase the hepatic MDA in rats in comparison to control group and Aspartame administration significantly elevated the MDA level $(\mathrm{P}<0.05)$. Stevia treatment, but not Aspartame, of diabetic rats decreased the MDA level when compared to diabetic group. (B) In comparison to diabetic rats, GSH level showed significant $(\mathrm{P}<0.05)$ increase with Stevia treated-diabetic group although more reduction in GSH level was observed with Aspartame treated-diabetic rats. (C) In comparison to diabetic rats, bcl-2 level showed significant $(\mathrm{P}<0.05)$ increase with Stevia treated-diabetic group although more reduction in bcl-2 level was observed with Aspartame treated-diabetic rats.
Effects of Stevia or Aspartame administration on hepatocyte injury induced by alloxan in diabetic rats

Light microscopic examination of liver sections from control and Stevia treated groups showed normal hepatic architecture with cords of hepatocytes radiating from the central vein. Portal tracts arranged at the periphery of the hepatic lobule which contained a branch of portal vein and a branch of bile duct (Fig. 2, A\&B). On the other hand, liver sections of Aspartametreated rats showed impaired liver cellular image as disturbed normal architecture with congestion in the central veins and sinusoids as well as periductal fibrosis surrounding the bile ducts (Fig. 2, C). Diabetic rats revealed dilatation and congestion in the central and portal veins accompanied with oedema and collagen proliferation as well as periductal fibrosis surrounding the dilated bile ducts at the portal area (Fig.2, D). Treatment of diabetic rats with Stevia improved the histological picture as mild dilatation was noticed in the portal vein with few oedema in the portal area. The hepatocytes and central veins were histologically normal (Fig. 2, E). On the other hand, treatment of diabetic with Aspartame aggravated the histological liver injury as appeared by the severely dilated central and portal veins as well as the sinusoids, while the portal area had oedema and collagen proliferation with periductal fibrosis surrounding the bile ducts. Focal haemorrhage was observed in the hepatic parenchyma (Fig.2, F\&G).

\section{Effects of Stevia or Aspartame administration on kidney injury induced by alloxan in diabetic rats}

Light microscopic examination of the kidney sections of the control and Stevia-treated groups showed normal glomerular tuft of capillaries, Bowman's space and epithelium. The proximal convoluted tubules (PCT) lined by cubical epithelium with a brush border and few nuclei with narrow lumen. The distal convoluted tubules (DCT) showed wider lumen and low cubical lining epithelial cells with centrally located nuclei. The lumen of distal convoluted tubule was wider with more defined lumen (Fig. 3, A\&B). However, by examining kidney sections of rats treated with Aspartame some degenerative changes were strikingly apparent within the renal corpuscles, proximal tubules and distal tubules. Focal inflammatory cells infiltration was noticed between the vacuolar degenerated tubules with congested cortical blood vessels (Fig. 3, C).

Diabetic rats revealed vacuolar degeneration in tubular cells and bleeding was noticed in some tubular lumen with peritubular infiltration (Fig. 3, D). Treatment of diabetic rats with Stevia improved the renal tissue picture, few degenerated tubules, almost absent cellular infiltration and no lumenal bleeding. Some congested blood vessels were noticed (Fig. 3, E). On the contradictory side, treatment of diabetic animals with Aspartame augmented renal destruction caused by alloxan. Glomeruli showed dilated capsular space, while diffuse vacuolar tubular degeneration and massive luminal tubular bleeding were also noticed (Fig. 3, F). 


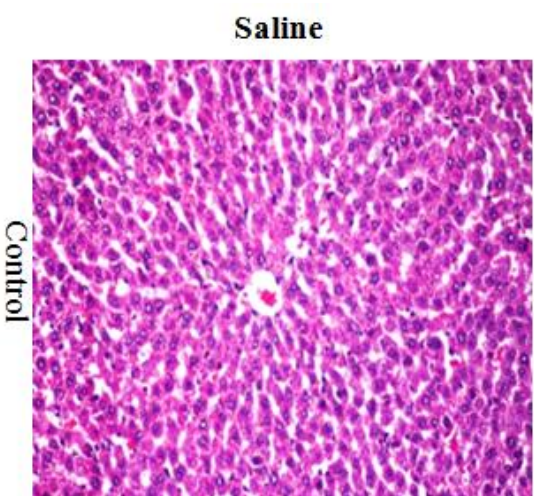

A

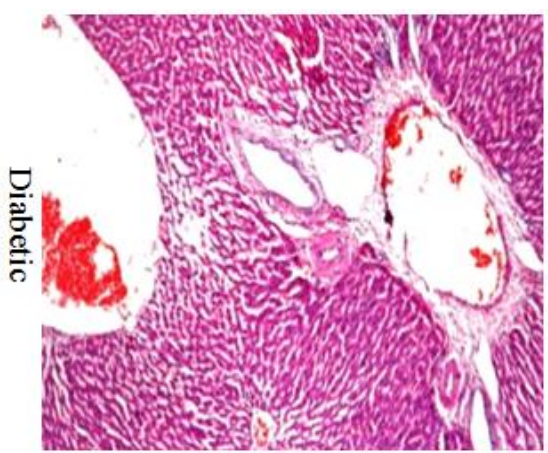

D
Stevia

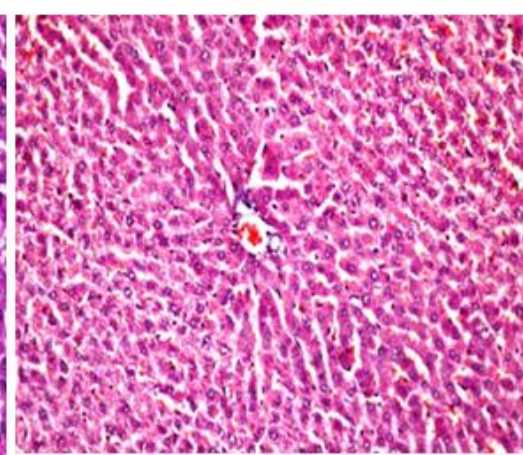

B

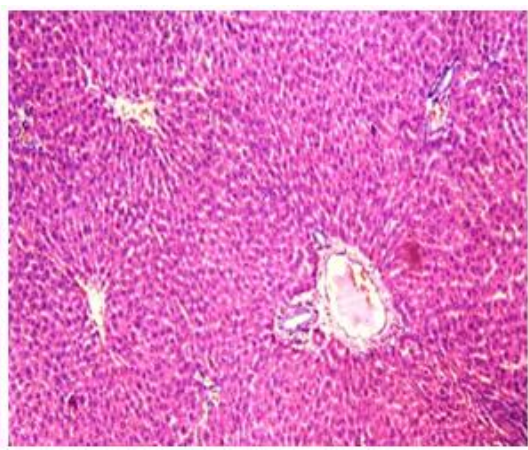

$\mathrm{E}$
Aspartame

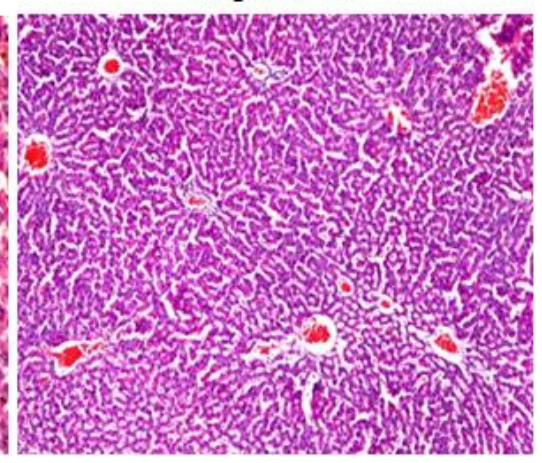

C

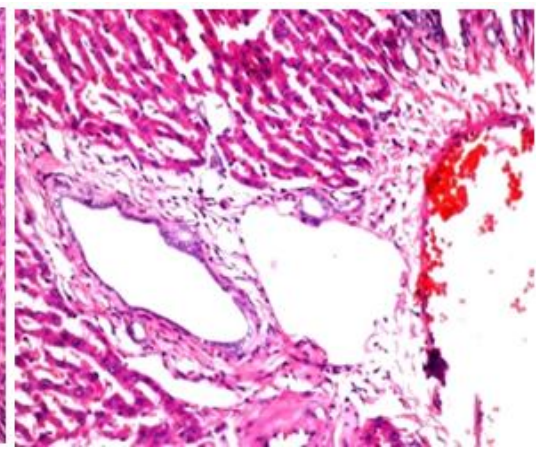

$\mathrm{F}$

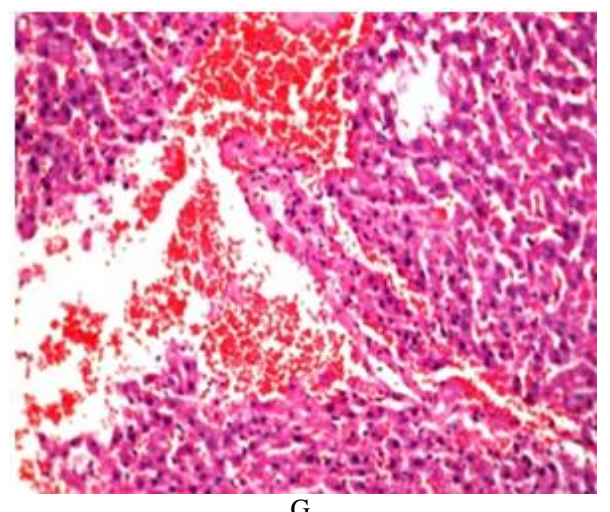

G

Fig. 2: Histopathological changes in liver.

Photomicrograph of a transverse section of liver of control group shows the hepatocytes arranged in cords radiating from the central vein (A). Photomicrograph of a transverse section of liver of Stevia treated group shows normal hepatic architecture (B). Photomicrograph of a transverse section of liver of Aspartame treated group shows congestion in the central veins and sinusoids (C). Photomicrograph of a transverse section of liver of alloxan administered (diabetic) group shows normal hepatic architecture dilatation and congestion in the central and portal veins associated with oedema and collagen proliferation. Periductal fibrosis surrounding the dilated bile ducts at the portal area were also noticed (D). Photomicrograph of a transverse section of liver of diabetic rats treated with Stevia shows normal histological picture of hepatocytes and central veins as well as mild dilatation in the portal vein with few oedema in the portal area (E). Photomicrograph of a transverse section of liver of diabetic rats treated with Aspartame shows aggravated liver injury as revealed by severely dilated central and portal veins as well as the sinusoids. The portal area oedema and collagen proliferation with periductal fibrosis surrounding the bile ducts were also noticed (F). Photomicrograph of a transverse section of liver of diabetic rats treated with Aspartame shows focal haemorrhage in the hepatic parenchyma indicating worsening of liver injury (G). (H.E.x100). 


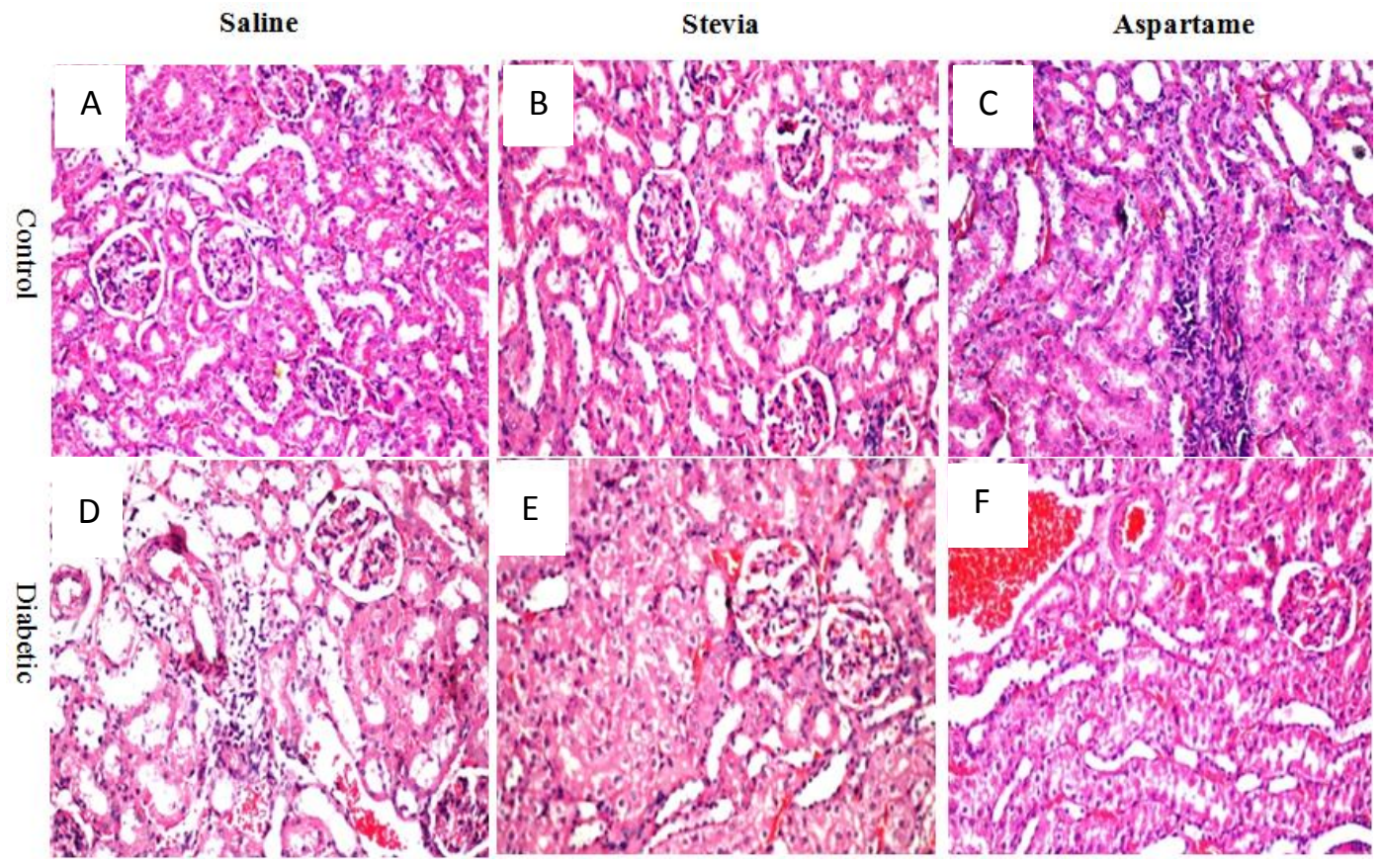

Fig. 3: Histopathological changes in kidneys

H \& E stained sections of kidney from control rats showed the normal glomeruli, Bowman's space, PCT and DCT (A). Photomicrograph of a kidney section of Stevia treated rats shows normal kidney structure of glomeruli, Bowman's space, PCT and DCT (B). Photomicrograph of a kidney section of Aspartame treated rats shows vacuolar degenerated tubules with inflammatory cells infiltration and congested cortical blood vessels (C). Photomicrograph of a kidney section of alloxan administered rats shows vacuolar degenerated tubules, bleeding in some tubular lumens with peritubular infiltration (D). Photomicrograph of a kidney section of alloxan administered rats treated with Stevia revealing few vacuolar tubular degeneration and some congested blood vessels (E). Photomicrograph of a kidney section of alloxan administered rats treated with Aspartame showing massive renal damage, dilated capsular space, diffuse vacuolar tubular degeneration and massive luminal tubular bleeding (F). (H.E.x200).

\section{DISCUSSION}

In this study, we demonstrate that administration of low calorie sweeteners (Stevia and Aspartame) to diabetic rats decreased both food intake and body weight as compared to control group. These results were supported by the studies of Anton et al. (Anton et al., 2010). The observed data suggests that low calorie sweeteners can affect both lipids and carbohydrates metabolism as well as increase in energy expenditure. Contrary to our results of Aspartame, Feijo Fde et al. reported greater weight gain in adult rats supplemented with Aspartame (Feijo Fde et al., 2013). This discrepancy could be due to different experimental procedures. Also, the current study showed insignificant change in fasting blood glucose level of rats treated with Stevia and those given Aspartame compared with control group. Such finding is consistent with the observation of Shastry et al. (Shastry et al., 2012).

The present study showed marked increase in blood glucose levels after rats were injected with alloxan. A previous study (Etuk and Muhammed, 2010) attributed this increase in glucose levels to the release of ROS induced by alloxan, with a simultaneous massive increase in cytosolic calcium concentration, leading to a quick destruction of $\beta$-cells of the pancreas which reduces the synthesis/release of insulin. In the current study, treatment of diabetic rats with Stevia and Aspartame showed significant reduction of blood glucose levels, with marked reduction in Aspartame group compared to Stevia (Table 1). In previous studies, the glucose lowering effect was attributed to the presence of sweet glycosides; stevioside and related compounds which enhance insulin secretion and utilization in diabetics which exhibit a protective action towards the pancreas (Jeppesen et al., 2002) in addition to increasing insulin sensitivity (Lailerd et al., 2004). Stevia exerts hypglycaemic, insulinotropic, and glucagonostatic actions in type-II diabetic rats (Jeppesen et al., 2002; Shukla et al., 2011). Therefore, the possible mechanistic effect of Stevia in lowering the glucose level could be through different mechanisms. The hypoglycemic effect of Aspartame is due to the release of glucagon-like peptide-1 and glucosedependent insulinotropic polypeptide hormones which increase insulin release from $\beta$-cells (Jang et al., 2007).

We demonstrated that administration of Aspartame causes liver and kidney dysfunction in normal and diabetic rats. There was marked increase in ALT, AST and ALP as well as urea and creatinine which was confirmed by the histopathological examination of liver and kidney sections (Fig. 2\&3). The increase of these biomarkers levels indicate an enhanced permeability, tissue damage or necrosis due to formation of free radicals in all tissues from glucose auto-oxidation and protein glycosylation (Chaitanya et al., 2010). The elevation of serum urea and creatinine could be due to a sudden decrease in glomerular 
filtration rate by the majority of methanol that enters proximal tubular epithelial cells binds to anionic phospholipids inducing abnormalities in function and metabolism of multiple intracellular membranes and organelles in these cells (Parthasarathy et al., 2006). On the other hand, treatment of normal and diabetic rats with Stevia showed no change in ALT, AST, ALP, urea and creatinine in normal rats and amelioration of their elevated levels in diabetic rats. Our present findings were also confirmed by histopathological examination that showed potential restoration of both liver and kidney architectures. Therefore, Stevia constituents could be responsible for the membrane stabilizing activity.

Glutathione, an important endogenous antioxidant system, is found in high concentration in liver and it is known to have key functions in protective cellular processes. Generation of ROS and lipid peroxides during diabetes-mediated oxidative stress could be correlated to decline in GSH levels and increase in levels of MDA in diabetic group (Parveen et al., 2010). Interestingly, we found that the development of Aspartame-hepatic and renal toxicity (Table 2) was associated with an increase in hepatic MDA and decrease in hepatic GSH in normal and diabetic rats (Fig. 1), indicating that oxidative stress plays a crucial role in the pathogenesis of Aspartame organ toxicity. In contrast, a significant decrease in hepatic MDA and increase in hepatic GSH levels were found in diabetic rats treated with Stevia. This finding indicates that Stevia had the potential to increase the biosynthesis of GSH which thereby reduces the oxidative stress and/or suppress the formation of lipid peroxidation byproducts (Singh et al., 2013).

In the current study, diabetic rat model showed an obvious decrease in hepatic level of anti-apoptotic marker, bcl-2. Our present data are consistent with a previous study (Alabdan, 2016) which suggested that oxidative stress, which starts with the onset of diabetes mellitus and increases progressively, can induce apoptosis. The decrease in hepatic level of anti-apoptotic factor bcl-2 of diabetic rats in the current study could be related to the decrease in GSH level. Reactive species associated diabetes can oxidize cellular GSH or induce its export outside the cell causing the loss of intracellular redox homeostasis and activation of the apoptotic signaling cascade (Circu and Aw, 2012).

Administration of Aspartame in both normal and diabetic rats showed marked decrease in hepatic bcl-2. Therefore, Aspartame might be harmful at cellular level and have the potential to induce apoptosis. In agreement with our results, Ashok and Sheeladevi demonstrated that exposure to Aspartame could change the antioxidant status and induce apoptotic changes in the brain by triggering the transactivation of proapoptotic proteins (Bax and Bad) as well as the suppression of bcl-2 (Ashok and Sheeladevi, 2014).

On the other hand, diabetic rats treated with Stevia extract showed marked increase in bcl-2. The present finding was supported by in vivo study, which demonstrates that Stevioside inhibits the release of cytokines, caspase- 3 and Bax versus a significant increase in bcl-2 level in mice (Wang et al., 2014). Thus, consumption of Stevia could maintain cell survival and counteract apoptosis. Further studies will be required to focus on herbal formulations of Stevia rebaudiana and Aspartame to determine their long-term effect, mechanism of action and pharmacokinetic.

\section{CONCLUSION}

Aspartame was found to be a more effective hypoglycemic agent than Stevia in diabetic rats. Marked deterioration of hepato-renal functions with Aspartame treatment versus significant protective effects of Stevia were observed. Although some countries still banned the use of Stevia since lack of toxicology profile, we and others credited Stevia with the various health benefits. Stevia rebaudiana may be therapeutically beneficial as hepato-renal protective agent for those suffering from diabetes mellitus.

\section{ACKNOWLEDGEMENTS}

The authors would like to thank Professor Dr. Adel Shalaby, Prof. of Physiology, Al-Azhar University (Cairo-Egypt), for his professional guidance and support throughout the progress of this article.

\section{Financial support and sponsorship: Nil.}

Conflict of Interests: There are no conflicts of interest.

\section{LIST OF ABBREVIATIONS}

AST: aspartate transaminase; ALT: alanine transaminase; ALP: alkaline phosphatase; MDA; Malondialdehyde; GSH: glutathione; ROS: Reactive oxygen species; SEM: Standard Error of Mean.

\section{REFERENCES}

Abhilash M, Paul MV, Varghese MV, Nair RH. Effect of long term intake of aspartame on antioxidant defense status in liver. Food Chem Toxicol, 2011; 49:1203-1207.

Abo Elnaga NIE, Massoud, M. I., Yousef MI, Mohamed HHA. Effect of stevia sweetener consumption as non-caloric sweetening on body weight gain and biochemical's parameters in overweight female rats. Annals of Agricultural Sciences 2016; 61:155-163.

Ahmed MB, Ahmed MI, Meki AR, Abdraboh N. Neurotoxic effect of lead on rats: Relationship to Apoptosis. Int J Health Sci (Qassim), 2013; 7:192-199.

Alabdan MA. Silymarin ameliorates liver damage by modulating oxidative stress and apoptosis in liver of streptozotocininduced diabetic rats. Int J Adv Res, , 2016; 4:1935-1942.

Alkafafy Mel S, Ibrahim ZS, Ahmed MM, El-Shazly SA. Impact of aspartame and saccharin on the rat liver: Biochemical, molecular, and histological approach. Int J Immunopathol Pharmacol, $2015 ; 28: 247-255$.

Anton SD, Martin CK, Han H, Coulon S, Cefalu WT, Geiselman $\mathrm{P}$, et al. Effects of stevia, aspartame, and sucrose on food intake, satiety, and postprandial glucose and insulin levels. Appetite, 2010; 55:37-43.

Ashok I, Sheeladevi R. Biochemical responses and mitochondrial mediated activation of apoptosis on long-term effect of aspartame in rat brain. Redox Biol, 2014; 2:820-831.

Aykac M, Uysal M, Yalcin AS. The effect of chronic ethanol ingestion on hepatic lipid peroxide, glutathione peroxidase and glutathione transferase in rats. Toxicology, $1985 ; 36: 71-76$. 
Babson AL, Greeley SJ, Coleman CM, Phillips GE. Phenolphthalein monophosphate as a substrate for serum alkaline phosphatase. Clin Chem, 1966; 12:482-490.

Bray GA, Nielsen SJ, Popkin BM. Consumption of highfructose corn syrup in beverages may play a role in the epidemic of obesity. Am J Clin Nutr, 2004; 79:537-543.

Buege JA, Aust SD. Microsomal lipid peroxidation. Methods Enzymol, 1978; 52:302-310.

Carvalho ENd, Carvalho NASd, Ferreira LM. Experimental model of induction of diabetes mellitus in rats. Acta Cirurgica Brasileira, 2003; 18:60-64.

Chaitanya KV, Pathan AAK, Mazumdar SS, Chakravarthi GP, Parine N, Bobbar ala V. Role of oxidative stress in human health. An overview. . J Pharm Res, 2010; 3:330-1333.

Chatsudthipong V, Muanprasat C. Stevioside and related compounds: therapeutic benefits beyond sweetness. Pharmacol Ther, 2009; 121:41-54

Circu ML, Aw TY. Glutathione and modulation of cell apoptosis. Biochim Biophys Acta, 2012; 1823:1767-1777.

De la Hunty A, Gibson S, Ashwell M. A review of the effectiveness of aspartame in helping with weight control. British Nutr Found Nutr Bull 2006; 31:115-128.

Etuk E, Muhammed B. Evidence-based analysis of chemical method of induction of diabetes mellitus in experimental animals. Asian $\mathrm{J}$ Exp Biol, 2010; 1:331-336.

Federiuk IF, Casey HM, Quinn MJ, Wood MD, Ward WK. Induction of type-1 diabetes mellitus in laboratory rats by use of alloxan: route of administration, pitfalls, and insulin treatment. Comp Med, 2004; 54:252-257.

Feijo Fde M, Ballard CR, Foletto KC, Batista BA, Neves AM, Ribeiro MF, et al. Saccharin and aspartame, compared with sucrose, induce greater weight gain in adult Wistar rats, at similar total caloric intake levels. Appetite, 2013; 60:203-207.

Gill GW. Gill hematoxylins: first person account. Biotech Histochem, 2010; 85:7-18.

Goyal SK, Samsher., Goyal RK. Stevia (Stevia rebaudiana) a bio-sweetener: a review. Int J Food Sci Nutr, 2010; 61:1-10.

Gregersen S, Jeppesen PB, Holst JJ, Hermansen K. Antihyperglycemic effects of stevioside in type 2 diabetic subjects. Metabolism, 2004; 53:73-76.

Gupta E, Purwar S, Sundaram S, Rai G. Nutritional and therapeutic values of Stevia rebaudiana: A review. J Med Plant Res, 2013; 7:3343-3353.

Henry J (1991) Clinical diagnosis and management. 18th edn. Philadelphia, W.B. Saunders Company.

Humphries P, Pretorius E, Naude H. Direct and indirect cellular effects of aspartame on the brain. Eur J Clin Nutr, 2008; 62:451-462.

Jang HJ, Kokrashvili Z, Theodorakis MJ, Carlson OD, Kim BJ, Zhou J, et al. Gut-expressed gustducin and taste receptors regulate secretion of glucagon-like peptide-1. Proc Natl Acad Sci U S A, 2007; 104:15069-15074.

Jeppesen PB, Gregersen S, Alstrup KK, Hermansen K. Stevioside induces antihyperglycaemic, insulinotropic and glucagonostatic effects in vivo: studies in the diabetic Goto-Kakizaki (GK) rats. Phytomedicine, 2002; 9:9-14.

Lailerd N, Saengsirisuwan V, Sloniger JA, Toskulkao C, Henriksen EJ. Effects of stevioside on glucose transport activity in insulinsensitive and insulin-resistant rat skeletal muscle. Metabolism, 2004; 53:101-107.

Magnuson BA, Burdock GA, Doull J, Kroes RM, Marsh GM, Pariza MW, et al. Aspartame: a safety evaluation based on current use levels, regulations, and toxicological and epidemiological studies. Crit Rev Toxicol, 2007; 37:629-727.

Mattes RD, Popkin BM. Nonnutritive sweetener consumption in humans: effects on appetite and food intake and their putative mechanisms. Am J Clin Nutr, 2009; 89:1-14.

Niedowicz DM, Daleke DL. The role of oxidative stress in diabetic complications. Cell Biochem Biophys, 2005; 43:289-330.
Parthasarathy NJ, Kumar RS, Manikandan S, Devi RS. Methanol-induced oxidative stress in rat lymphoid organs. J Occup Health, 2006; 48:20-27.

Parveen K, Khan MR, Mujeeb M, Siddiqui WA. Protective effects of Pycnogenol on hyperglycemia-induced oxidative damage in the liver of type 2 diabetic rats. Chem Biol Interact, 2010; 186:219-227.

Pol J, Hohnova B, Hyotylainen T. Characterisation of Stevia rebaudiana by comprehensive two-dimensional liquid chromatography time-of-flight mass spectrometry. J Chromatogr A, 2007; 1150:85-92.

Reitman S, Frankel S. A colorimetric method for the determination of serum glutamic oxalacetic and glutamic pyruvic transaminases. Am J Clin Pathol, 1957; 28:56-63.

Shastry CS, Yatheesh CK, Aswathanarayana BJ. Comparative evaluation of diabetogenic and mutagenic potential of artificial sweeteners-aspartame, acesulfame-k and sucralose. Nitte University J Health Sci, , 2012; 2:80-84

Shukla S, Mehta A, Mehta P, Bajpai VK. Evaluation of comparative antidiabetic effects of ethanolic extracts of Caesalpinia bouncucella and Stevia rebaudiana in normal and alloxan induced experimental rats. Rom Biotechnol Lett, 2011; 16:6187-6199.

Singh S, Garg V, Yadav D. Antihyperglycemic and antioxidative ability of Stevia rebaudiana (bertoni) leaves in diabetes induced mice. International Journal of Pharmacy and Pharmaceutical Sciences, 2013; 5:297-302.

Suresh Y, Das UN. Protective action of arachidonic acid against alloxan-induced cytotoxicity and diabetes mellitus. Prostaglandins Leukot Essent Fatty Acids, 2001; 64:37-52.

Swithers SE, Davidson TL. A role for sweet taste: calorie predictive relations in energy regulation by rats. Behav Neurosci, 2008; 122:161-173.

Toora BD, Rajagopal G. Measurement of creatinine by Jaffe's reaction--determination of concentration of sodium hydroxide required for maximum color development in standard, urine and protein free filtrate of serum. Indian J Exp Biol, 2002; 40:352-354.

Van den Eeden SK, Koepsell TD, Longstreth WT, Jr., van Belle G, Daling JR, McKnight B. Aspartame ingestion and headaches: a randomized crossover trial. Neurology, 1994; 44:1787-1793.

Viana GS, Medeiros AC, Lacerda AM, Leal LK, Vale TG, Matos FJ. Hypoglycemic and anti-lipemic effects of the aqueous extract from Cissus sicyoides. BMC Pharmacol, 2004; 4:9.

Wang T, Song X, Zhang Z, Guo M, Jiang H, Wang W, et al. Stevioside inhibits inflammation and apoptosis by regulating TLR2 and TLR2-related proteins in S. aureus-infected mouse mammary epithelial cells. Int Immunopharmacol, 2014; 22:192-199.

Whitehouse CR, Boullata J, McCauley LA. The potential toxicity of artificial sweeteners. AAOHN J, 2008; 56:251-259.

Wild S, Roglic G, Green A, Sicree R, King H. Global prevalence of diabetes: estimates for the year 2000 and projections for 2030. Diabetes Care, 2004; 27:1047-1053.

Zaman MM, Chowdhury MAH, Chowdhury T. Growth parameters and leaf biomass yield of stevia (Stevia rebaudiana, Bertoni) as influenced by different soil types of Bangladesh. J Bangladesh Agril Univ, 2015; 13:31-37.

How to cite this article:

AbdElwahab AH, Yousuf AF, Ramadan BK, Elimam H. Comparative Effects of Stevia rebaudiana and Aspartame on hepato-renal function of diabetic rats: Biochemical and Histological Approaches. J App Pharm Sci, 2017; 7 (08): 034-042. 